\title{
MARTABAT MANUSIA SEBAGAI BASIS ETIS MASYARAKAT MULTIKULTURAL
}

\author{
Otto Gusti Madung*
}

\begin{abstract}
Since the issue of the war against global terrorism emerged, the discourse surrounding the concept of human dignity returns as a normative basis for the protection of basic human rights. The term human dignity has existed since the days of ancient Greek philosophy and was further developed in dialogue with medieval Christian theology and the secular thought of modern times. This article places special emphasis on the understanding of human dignity as defined by a secular thinker and exponent of the Enlightenment, Immanuel Kant. The concept of human dignity as developed by Immanuel Kant is rational and transcends the boundaries of religions, cultures and ideologies; therefore it is suitable as a normative basis for a multicultural society. But the article also does not turn a blind eye to some critical observations offered by adherents of particular ethics concerning the Kantian universal ethics. These critical observations emphasize the ethical principle of substantial solidarity in order to overcome the dangers of anonymity in each model of formal ethics.
\end{abstract}

Keywords: Human dignity, multiculturalism, imperative, ethics, human rights.

Abstrak: Sejak isu perang melawan terorisme global muncul, wacana seputar konsep martabat manusia kembali menjadi aktual sebagai basis normatif dalam melindungi hak-hak dasar manusia. Istilah martabat manusia sudah lahir sejak zaman Yunani kuno dan dalam perjalanan sejarah berdialog dengan pandangan teologi Kristen Abad Pertengahan serta pemikiran sekular abad modern. Tulisan ini mencoba memberikan penekanan khusus pada pemahaman tentang martabat manusia seperti dirumuskan oleh pemikir sekular abad pencerahan yakni Immanuel

* Otto Gusti Madung, Sekolah Tinggi Filsafat dan Teologi Katolik, Ledalero, Maumere, Flores, NTT. E-mail:ottomadung@hotmail.com. 
Kant. Konsep martabat manusia yang dikembangkan oleh Immanuel Kant bersifat rasional dan melampaui sekat-sekat agama, ideologi dan budaya; sehingga dipandang layak untuk dijadikan basis normatif sebuah masyarakat multikultural. Akan tetapi, penulis juga tidak menutup mata terhadap beberapa catatan kritis yang diberikan oleh beberapa pengikut etika khusus berkaitan dengan etika universal Kant. Catatancatatan kritis tersebut menekankan aspek solidaritas substansial dalam etika untuk mengatasi bahaya-bahaya anonimitas dalam setiap model etika formal.

Kata-kata Kunci: Martabat manusia, multikulturalitas, imperatif, etika, hak-hak asasi manusia.

\section{PENDAHULUAN}

Pembicaraan tentang martabat manusia (Menschenwürde) kembali aktual pada awal abad ke-21 dalam perang melawan terorisme global. Martabat manusia dipandang sebagai titik tolak pendasaran normanorma. Perlakuan keji terhadap para teroris yang berada dalam tahanan Amerika Serikat di Guantanamo Bay membuat masyarakat global marah. Sejahat-jahatnya seorang teroris ia harus tetap diperlakukan sebagai manusia karena kejahatannya tidak pernah dapat menghapus status "martabat" kemanusiaannya.

Di Jerman, konsep "martabat manusia" kembali meramaikan perdebatan publik pada 2006 ketika Mahkamah Konstitusi Jerman atas nama faham martabat manusia dalam konstitusi-menolak berlakunya Undang-undang Pertahanan Udara (Luftsicherheitsgesetz) yang telah disahkan oleh Parlemen Jerman. Ketika menyusun dan mengesahkan undang-undang ini Parlemen Jerman membayangkan skenario "9/11" ketika para teroris menghancurkan menara kembar World Trade Center. Dengan undang-undang ini parlemen sesungguhnya ingin memberikan kuasa kepada pihak keamanan untuk menembak jatuh pesawat penumpang yang diketahui membawa bom teroris. Tujuannya ialah untuk melindungi manusia dalam jumlah yang lebih 
besar yang menjadi tujuan serangan teroris seperti yang terjadi di Word Trade Center.

Mahkamah Konstitusi berpendapat, pembunuhan atas penumpang pesawat sipil oleh aparat negara bertentangan dengan hukum. Kewajiban negara untuk menyelamatkan hidup korban potensial terorisme harus ditempatkan pada level sesudah kewajiban untuk menghormati martabat para penumpang pesawat sipil tersebut. Jika negara secara sepihak menentukan hidup mereka, negara telah menyangkal nilai yang dimiliki setiap manusia karena kemanusiaannya. Dalam bahasa Kantian, prinsip martabat manusia melarang keras setiap negara untuk menjadikan individu sebagai instrumen untuk tujuan tertentu. ${ }^{1}$

Dewasa ini konsep martabat manusia sudah diterima secara internasional seiring dengan diadopsinya faham hak-hak asasi manusia ke dalam konstitusi negara-negara modern, termasuk negara Indonesia. Martabat manusia merupakan sebuah konsep etis yang dapat menjadi basis kehidupan bersama dalam sebuah masyarakat multikultural. Karena itu, konsep ini menjadi relevan untuk bangsa Indonesia. Tulisan ini coba menunjukkan sejarah perkembangan, pengertian, dan relevansi konsep ini untuk sebuah masyarakat multikultural.

\section{SEJARAH KONSEP MARTABAT MANUSIA}

Konsep martabat manusia sesungguhnya bukan konsep modern. Pada zaman Romawi Kuno, Cicero (106-43 SM) sudah bicara tentang martabat manusia. Menurut Cicero martabat manusia melekat dalam kodratnya sebagai makhluk berakal budi. ${ }^{2}$ Kodrat intelektual ini membuat manusia menempati posisi khusus di tengah alam ciptaan dan di antara makhluk ciptaan lainnya. Dalam refleksi filosofis dan teologis Abad Pertengahan basis pemahaman martabat manusia adalah ide

1 Bdk. Jürgen Habermas, Zur Verfassung Europas: Ein Essay (Frankfurt am Main: Suhrkamp, 2011), S. 14.

2 Bdk. Franco Volpi, Hrsg., Grosses Werklexikon der Philosophie, Band 1: A bis K, (Stuttgart: Alfred Kröner Verlag, 2007), SS. 298 usw. 
tentang manusia sebagai gambaran Allah yang menjadi titik pijak partisipasi manusia dalam akal budi ilahi. Dominasi agama Abad Pertengahan perlahan-lahan bergeser dan diroboh-kan oleh terpaan gelombang sekularisasi Abad Pencerahan. Perubahan ini diikuti dengan pergeseran paradigma antropologis. Manusia Abad Pencerahan adalah manusia otonom dan di atas singgasana otonomi ini berdiri tegak faham martabat manusia.

Pada abad ke-15, misalnya, Pico della Mirandolla mengartikan citra Allah sebagai pencipta. Sebagai citra Allah manusia adalah pencipta dirinya sekaligus pencipta dunia yang baru. Hakikat citra Allah bukan saja terungkap lewat akal budi, melainkan lewat keniscayaan bahwa manusia mampu merumuskan sendiri hukum moral. Demikian pun eksistensi manusia di tengah kosmos bukan lagi sebuah keterberian. Menurut della Mirandolla, manusia tidak memiliki kodratnya sendiri, tetapi ia harus mendefinisikannya seturut kehendak bebas. Di sini della Mirandolla mentransformasikan konsep teologis citra Allah menjadi konsep sekular tanpa kehilangan substansinya. Usaha ini merupakan sebuah contoh dialog yang berhasil antara agama dan pemikiran sekular.

Selanjutnya della Mirandolla menjelaskan bahwa benar jika manusia ditempatkan di tengah dunia agar ia mampu memandang dunia sekelilingnya. Namun ia bebas untuk menata bentuk hidupnya yang wajar. Manusia adalah model sekaligus penata hidupnya sendiri. Manusia dapat mentransendensikan dirinya mendekati yang Ilahi, tetapi juga turun menyerupai binatang. ${ }^{3}$ Martabat manusia bukan terletak pada prioritas ontologis atau kemampuan kusus (seperti akal budi) yang dimilikinya, tetapi pada kebebasannya untuk mengembangkan diri. Manusia sebagai tuan atas dirinya dan alam semesta merupakan konsep antropologis yang mewarnai seluruh zaman modern.

3 Bdk. Heinz Paetzold, "Der Mensch," in Martens Ekkehard/Herbert Schnädelbach, Hrsg., Philosophie. Ein Grundkurs (Hamburg: Reinbek, 1985), S. 448. 
Pada abad ke-18 konsep martabat manusia dirumuskan sebagai basis faham hak-hak asasi manusia (HAM) yang memiliki validitas universal. Itu berarti, HAM berlaku kapan saja, di mana saja dan bagi setiap individu tanpa pengecualian. Secara logis tuntutan validitas seperti ini hanya mungkin dipikirkan jika HAM dipahami secara formal-abstrak dan dilucuti dari segala substansi dan rumusan-rumusan konkret. Inilah kekhasan konsep moral masyarakat modern. Hal yang sama berlaku juga untuk pandangan modern tentang hukum kodrat seperti tercermin dalam pergeseran paradigma dari nilai-nilai keutamaan etis menuju norma-norma formal deontologis, seperti dirumuskan Habermas:

Jika dalam konsep hukum kodrat klasik norma-norma hukum dan moral secara substansial berorientasi pada konsep hidup baik atau keutamaan etis warga, maka hukum formal modern dibebaskan dari katalog kewajiban tatanan hidup material, entah itu kewajiban suku atau kota. Hukum formal melegitimasi adanya sebuah ranah kebebasan individual yang netral, di dalamnya setiap individu secara egoistis dapat mengejar keuntungan-keuntungan pribadi. Hukum formal pada prinsipnya merupakan hukum kebebasan, karena ia harus mengizinkan semua tindakan yang secara eksplisit tidak dilarang berdasarkan kriteriakriteria perilaku eksternal. Hobbes sudah merumuskan secara jelas bahwa izin yang tidak langsung ini mengungkapkan kebebasan menurut undang-undang formal. Dan Locke mendefinisikan tujuan undangundang tersebut sebagai penguasaan atas hak milik privat yang juga mencakup hak hidup dan kebebasan. ${ }^{4}$

Pada awal abad modern konsep martabat manusia dikonkretisasikan secara formal lewat deklarasi hak dasar atas milik. Hak milik di sini mencakup kepemilikan atas tubuh dan barang-barang. Pernyataan "kepemilikan atas tubuh" memiliki konsekuensi etis luar biasa bagi para budak. Para budak berhak atas tubuhnya dan bukan majikan, sehingga praktik perbudakan dilihat sebagai pelecehan terhadap martabat manusia.

Konsep hak milik yang dirumuskan pada abad modern melahirkan pandangan tentang hak milik yang bersifat individualistis. Individualisme

4. Jürgen Habermas, Theorie und Praxis: Sozialphilosophische Studien (Frankfurt am Main: Suhrkamp, 1982), S. 90. 
ini dalam perkembangannya menjadi titik pijak pemahaman hak-hak asasi manusia yang telah menjadi bahan perdebatan hingga dewasa ini. Bahkan perdebatan tersebut sering bermuara pada kesulitan untuk menerima konsep hak-hak asasi manusia pada tataran global. Kita ingat akan penolakan atas nama nilai-nilai komuniter masyarakat Asia atas konsep hak-hak asasi manusia yang dianggap liberal dan individualistis.

Deklarasi Universal Hak-hak Asasi Manusia pada 10 Desember 1948 mengungkapkan sintesis antara substansi hukum kodrat dari abad ke18 dan pengalaman penindasan oleh rejim totalitarian pada abad ke20. Dalam deklarasi ini "martabat manusia" dan hak-hak manusia yang setara dan tak terlucuti diakui sebagai titik pijak kebebasan, keadilan dan perdamaian. Pelecehan atas prinsip etis ini akan menghantar umat manusia menuju kekelaman peradaban barbarian di mana kondisi bebas dari rasa takut dan penderitaan serta kebebasan berekspresi dan beriman masih jauh panggang dari api.

Untuk mengakhiri peradaban barbarian ini dibutuhkan keyakinan teguh akan prinsip hak-hak asasi manusia dan martabat serta nilai pribadi manusia. Krisis peradaban pada pertengahan abad ke-20 disebabkan oleh rezim fasis dan sosialisme nasional yang melanda negara-negara Eropa dan Asia. Belajar dari krisis ini, sejumlah negara Barat demokratis mengadopsi ide normatif hak-hak asasi manusia ke dalam konstitusinya. Dengan demikian, substansi etis konsep martabat manusia juga turut mempengaruhi konstitusi negara-negara Eropa. Martabat manusia berkembang menjadi norma fundamental. Bagi Mahkamah Konstitusi Jerman, misalnya, konsep martabat manusia dipandang sebagai kriteria normatif semua keputusan hukum dan tafsiran juridis. Konsep ini juga dianggap sebagai poros sistem nilai konstitusi. ${ }^{5}$ Pandangan ini dipengaruhi oleh konsep Kantian bahwa norma dan nilai harus menjadi pilar penopang semua keputusan hukum, politis dan perundangundangan. Legalitas saja tidak cukup. Untuk itu dibutuhkan legitimasi

5 Bdk. Franz-Peter Burkard, “Würde," in Peter Precht/Franz-Peter Burkard, Hrsg., Metzler Lexikon Philosophie (Stuttgart/Weimer: Verlag J.B. Metzler, 1999), S. 673. 
moral yang menjadi basis tindakan baik pada tataran individual, politis, maupun sosial.

\section{PENGERTIAN TENTANG MARTABAT MANUSIA}

Di puncak pencerahan Eropa Immanuel Kant bertahta sebagai pemikir martabat manusia dan juga sebagai mahkota filsafat moral modern. ${ }^{6}$ Pengertian martabat manusia yang banyak dianut hingga kini berasal dari Kant. Ia melegitimasi kekuasaan manusia atas alam dari perspektif moral. Bahkan Kant melihat kekuasaan atas alam sebagai hak moral manusia.

Namun bukan manusia sebagai manusia yang dimaksudkan Kant, melainkan manusia sebagai subjek moralitas. "Hanya manusia sebagai persona, itu berarti sebagai subjek akal budi moral-paktis, manusia melampaui segala harga; karena sebagai persona ia dipandang sebagai tujuan pada dirinya sendiri, ia memiliki martabat (sebuah nilai intrinsik absolut)." ${ }^{7}$ Privilese yang dimiliki manusia di sini tidak dipahami sebagai hak khusus, tetapi lebih sebagai kewajiban.

Kekhasan manusia tampak sebagai makhluk bermoral. Kemampuan moral manusia terbaca dalam dua pengertian: dalam kemampuan untuk bertindak secara moral dan dalam kepekaan untuk merasa malu dan merasa bersalah jika melakukan pelanggaran moral. Kant sendiri menulis: "Manusia dan bahkan setiap makhluk rasional hidup sebagai tujuan dalam dirinya, bukan sekedar alat yang dipakai untuk keinginan tertentu, ia harus dipandang sebagai tujuan dalam semua tindakannya, baik yang diarahkan untuk dirinya maupun untuk orang lain." ${ }^{8}$

Sebuah tujuan dalam dirinya tidak sama dengan barang di pasar yang memiliki harga atau objek selera yang dapat selalu berubah-ubah.

6 Bdk. Ottfried Höffe, Medizin ohne Ethik? (Frankfurt am Main: Suhrkamp Verlag, 2002), S. 64 .

7 Immanuel Kant, Die Metaphysik der Sitten. Zweiter Teil: Metaphysische Anfangsgrûnde der Tugendlehre (1798) (Stuttgart: Philipp Reclam Verlag, 2001), S. 319.

8 Immanuel Kant, Grundlegung zur Metaphysik der Sitten (1785), Alexander Heine, Hrsg. (Essen: Phaidon Verlag, 1992), S. 76. 
Setiap manusia memiliki nilai dalam dirinya yang tidak dapat ditukar dengan apa pun. Karena "melampaui segala harga," manusia tidak pernah boleh dijadikan instrumen. Manusia adalah makhluk yang ada dan bertindak demi dirinya. Ia pun harus diperlakukan sebagai tujuan dalam dirinya. Itulah esensi manusia sebagai manusia yang juga dikenal dengan humanitas.

Martabat manusia memiliki aspek personal dan sosial. Kedua aspek ini saling berkaitan. Hal itu tidak berarti bahwa seorang manusia yang hidup radikal sebatang kara, seperti dalam kisah Robinson Crusoe, tidak memiliki martabat. Kendatipun hampir semua antropolog sepakat bahwa figur Robinson Crusoe hanya ada dalam mitos ataupun bahwa manusia solipsistis itu sungguh-sungguh eksis dan memiliki kemampuan moral, ia pasti bermartabat dan karena itu memiliki nilai dalam dirinya. ${ }^{9}$

Setiap manusia sebagai tujuan dalam dirinya membutuhkan pengakuan dari yang lain dan dari dirinya. Pengakuan tersebut bersifat timbal balik. Namun, hilangnya pengakuan tidak mampu membatalkan martabat dalam diri manusia. Maka, seorang penjahat kelas kakap tidak pernah kehilangan martabatnya dan tetap harus diperlakukan sebagai tujuan dalam dirinya. Karena itu, hukuman mati tidak diperbolehkan dan bertentangan dengan prinsip martabat manusia.

Kendati melekat pada kodrat manusia, martabat manusia membutuhkan penghargaan dari sesama. Karena itu, martabat manusia rentan untuk dilecehkan. Pelecehan terhadap martabat manusia tidak pernah dapat dibenarkan. Kapan dan di mana saja pelecehan terhadap martabat manusia, diskriminasi dan kekerasan dipandang sebagai kejahatan dan tidak dapat dibiarkan, entah itu diskriminasi atas nama agama, etnik, budaya atau atas alasan kesehatan. Setiap manusia, hanya karena kemanusiaannya, harus dipandang setara dengan yang lain.

Kant berpandangan bahwa barangsiapa melecehkan martabatnya sendiri, ia melanggar kewajiban moral terhadap diri sendiri. Sedangkan

9 Bdk. Ottfried Höffe, Medizin ohne Ethik?, S. 67. 
mereka yang melukai mertabat sesama, mengabaikan bukan saja kewajiban moral tetapi juga kewajiban hukum terhadap yang lain. Pelecehan terhadap martabat manusia di mana saja dipandang jahat, entah objek pelecehan adalah orang-orang yang tak dapat memperjuangkan haknya seperti bayi, entah orang-orang gila atau para budak. Basis etis pengakuan martabat manusia adalah keanggotaan pada genus manusia. Setiap makhluk yang berwajah manusia memiliki martabat dan berhak mendapatkan pengakuan atasnya.

Seperti diuraikan di atas, Kant membangun refleksi etis atas konsep martabat manusia secara sistematis. Kant berpendapat bahwa manusia adalah makhluk bebas dan kebebasan itu hanya menjadi nyata dalam proses penentuan diri atau proses penetapan hukum yang otonom. Hanya hukum otonom seperti ini mampu mengikat manusia. Untuk makhluk rasional, undang-undang yang mengikat hanyalah undangundang yang dibuatnya sendiri atau yang mendapat persetujuannya atas dasar pertimbangan rasional. Kant memikirkan otonomi dan universalitas keputusan rasional secara bersama-sama dan menempatkan keduanya pada posisi setara. Hanya lewat proses inilah kebebasan menjadi nyata. Jadi kebebasan tidak diungkapkan lewat kesewenangwenangan, melainkan tindakan atas dasar pertimbangan dan tujuantujuan yang ditetapkan secara rasional oleh individu. Atas dasar itulah manusia mampu bertindak secara moral.

Konsep otonomi ini dapat dijelaskan juga dari perspektif martabat manusia. Menurut Kant, bertindak karena dorongan-dorongan biologis atau nafsu bertentangan dengan kebebasan. Alasannya, dengan cara seperti itu tindakan tersebut didikte oleh kebutuhan-kebutuhan tersebut. Manusia bukan mesin otomatis atau makhluk yang hanya mengejar kepentingan dirinya. Ia juga mampu menangkap sesuatu yang melampaui horizon kepentingan dirinya. Tindakan manusia tidak hanya didorong oleh keinginan untuk bertahan hidup, tetapi juga oleh solidaritas atau alasan altruistis. Dengan demikian, otonomi kehendak merupakan basis martabat manusia. Manusia bukan saja alat untuk tujuan tertentu 
(misalnya sebagai ciptaan di mana Allah adalah tujuannya). Manusia adalah tujuan dalam dirinya kapan dan di mana saja. Pengertian Kantian tentang martabat manusia mendefinisikan manusia sebagai tujuan dalam dirinya yang tidak boleh diinstrumentalisasikan.

Konsep martabat manusia dalam etika modern tidak lagi diberi pendasaran secara ontologis atau antropologis, melainkan normatif. Itu berarti, manusia memiliki martabat bukan karena anugerah Allah atau karena hadiah tatanan kosmos kodrati seperti tuntutan pendasaran ontologis atas dasar posisi manusia di tengah alam semesta. Martabat manusia juga bukan ciri dasariah manusia yang tidak dapat diganggu gugat atau dipandang sebagai kodrat manusia seperti tampak dalam pendasaran antropologis, sebab de facto martabat manusia sering digugat keberadaannya dan dilecehkan.

Dalam konsep filsafat moral modern martabat manusia hanya dapat dipikirkan sebagai sebuah nilai dasariah. Pengakuan atas nilai dasariah ini harus menjadi kriteria normatif realitas dan tindakan kita. Maka, jika kita secara rasional yakin bahwa martabat manusia yang lahir dari kemampuan penentuan diri secara bebas merupakan nilai terakhir yang berlaku absolut, kita akan bertindak lain dibandingkan dengan orang yang tidak menerimanya.

MARTABAT MANUSIA DAN MASYARAKAT MULTIKULTURAL

Dalam masyarakat plural dan multikultural pendasaran konsep martabat manusia tidak dapat berpijak pada agama, tradisi atau konvensi semata, sebab kekuatan argumentasi agama, tradisi dan konvensi selalu bersifat partikular. Hal ini menjadi problematis ketika konsep martabat manusia dijadikan alasan untuk menerapkan kewajiban intervensi etis ke dalam kebudayaan lain dan ketika akibat dari intervensi etis tersebut harus diberi legitimasi.

Hal yang sama juga berlaku dalam komunikasi antarbudaya. Pelanggaran HAM dan perlakuan tidak berperikemanusiaan terhadap 
kelompok-kelompok minoritas, perempuan atau kelompok marginal oleh penguasa atau golongan mayoritas merupakan alasan etis untuk melakukan intervensi dengan kekerasan. Intervensi seperti ini hanya dapat dipertanggungjawabkan atas dasar prinsip moral pasca tradisional atau pasca metafisik dengan tuntutan validitas universal. Dari perspektif prinsip moral pasca metafisik, tindakan etis tidak dilihat sebagai adat-istiadat atau kebiasaan dari tradisi atau budaya tertentu, melainkan prinsip yang memiliki validitas untuk semua umat manusia.

Prinsip moral Kantian menekankan universalitas faham martabat manusia. Prinsip ini terkandung dalam prinsip imperatif kategoris yang terdiri dari dua bagian, yakni tuntutan universalitas dan larangan instrumentalisasi. Adapun bunyi kedua imperatif tersebut: "Bertindaklah seturut maxim yang Anda sendiri dapat inginkan sebagai sebuah undangundang yang berlaku umum."10 Lalu rumusan kedua: "Bertindaklah sedemikian sehingga Anda menjadikan kemanusiaan, baik yang ada dalam dirimu sendiri maupun dalam diri orang lain, selalu sebagai tujuan dan bukan hanya sebagai sarana."11 Kedua prinsip ini bersifat universal dan tidak mengenal pengecualian. Prinsip moral Arthur Schopenhauer tentang perintah untuk berbela rasa terhadap seluruh makhluk hidup juga memiliki validitas universal: "Janganlah melukai yang lain; tetapi bantulah siapa saja sejauh Anda mampu."12 Imperatif etis Schopenhauer ini tidak berpijak pada pendasaran rasional, melainkan pada semacam "perasaan purba" (Urgefühl). Karena itu, menurut Schopenhauer, imperatif etis tersebut tidak bersifat mewajibkan secara absolut.

Dari uraian di atas, terutama dalam refleksi tentang konsep martabat manusia Kantian, kita dapat menarik benang merah: sebuah prinsip etika agar dapat mendapat pengakuan universal dan lintas budaya sekurang-kurangnya memiliki lima ciri dasariah berikut ini. Pertama,

10 Immanuel Kant, Grundlegung zur Metaphysik der Sitten, S. 67.

11 Immanuel Kant, Grundlegung zur Metaphysik der Sitten, S. 78.

12 Arthur Schopenhauer, "Preisschrift über die Grundlage der Moral," in Arthur Schopenhauer, Werke in zehn Bünden, Band 6 (Zürich: Haffsman Verlag AG, 1977), S. 177. 
rasionalitas. Norma tindakan harus merupakan hasil dari sebuah refleksi rasional agar dapat diterima secara global. Kedua, bebas dari kontradiksi. Itu berarti, sebuah maxim tindakan yang menegasi dirinya sendiri jika diuniversalisasikan sudah pasti tidak memiliki basis rasional yang cukup. Ketiga, formalitas. Norma dan nilai harus dirumuskan secara universal; artinya, norma atau nilai tersebut tidak boleh mengandung substansi khusus atau partikular. Keempat, bersifat pasca tradisional. Yang dipandang sebagai prinsip-prinsip moral rasional hanyalah prinsipprinsip yang dapat diakui atas dasar rasionalitasnya, dan bukan karena alasan validitas tradisional, efektivitas atau tatanan hirarkis. Kelima, etika universal merupakan kewajiban tanpa pengecualian, absolut, dan melampaui partikularitas budaya.

Syarat-syarat ini dipenuhi oleh konsep martabat manusia sehingga dapat diterima sebagai basis normatif dalam menyelesaikan konflik moral dalam sebuah masyarakat multikultural. Namun syarat-syarat universalitas etika di atas mendapat kritikan dari sudut pandang etika partikularistis. ${ }^{13}$ Etika partikular menegasi universalitas moral sambil mengusung nilai-nilai komunal, multikulturalitas dan realisme etis.

Menurut para penganut etika partikular, etika universal harus dibatalkan guna menyelamatkan nilai dan keutamaan komunal. Solidaritas substansial antara warga yang tidak setara dalam sebuah komunitas harus dihidupi dan mendapat prioritas berhadapan dengan prinsip kontrak sosial anonim dalam kesetaraan formal. Demikianpun hak kolektif untuk menggunakan bahasa daerah akan ambruk di bawah lindasan bahasa etika universal. Etika universal juga ditolak atas nama multikulturalitas. Hidup berdampingan dari nilai, ideologi dan cara hidup yang berbeda dianggap tidak kompatibel dengan kriteria-kriteria normatif universal. Setiap usaha untuk membangun tatanan moral universal akan berhadapan dengan kritikan-kritikan etnosentrisme atau terorisme budaya seperti sering dialami budaya Eropa. Karena nilai-

13 Bdk. Gerhard Schweppenhäuser, Grundbegriffe der Ethik zur Einführung (Hamburg: Junius Verlag GmbH, 2003), S. 154. 
nilai, norma, dan pandangan hidup bersifat partikular dan tidak dapat dipertemukan, sikap paling tepat untuk menghadapi pluralitas tersebut ialah realisme dalam bentuk pengakuan akan kebhinekaan tanpa mempersoalkannya.

Kritikan partikularisme etis atas universalitas prinsip etika umumnya dan konsep martabat manusia khususnya sesungguhnya bersifat ideologis dan secara epistemologis tidak dapat dipertanggungjawabkan. Secara epistemologis partikularisme terjebak dalam kontradiksi performatif. Partikularisme radikal hanya benar kalau ia salah. Partikularisme hanya dapat diterima kalau ia diakui sebagai sebuah tesis yang berlaku universal. Kritikan ini juga bersifat ideologis karena partikularisme menyembunyikan kepentingan-kepentingan tertentu. Relativisme etis abstrak seperti terungkap dalam prinsip "andere Länder, andere Sitten" (lain padang, lain belalang) tidak dapat dipertahankan di hadapan realitas kejahatan kemanusiaan atas nama budaya, seperti pembersihan etnis atau sunat terhadap perempuan, misalnya. ${ }^{14}$ Kejahatan-kejahatan seperti ini memaksa budaya lain untuk melakukan intervensi kemanusiaan. Intervensi kemanusiaan mengandaikan adanya basis legitimasi etis yang berlaku umum.

Di balik multikulturalitas radikal etika partikular sesungguhnya terselubung sikap anti egalitarianisme. Sikap ini lahir dari hasrat kekuasaan dan kepentingan ideologi agama. Atas nama ideologi agama sering kali tradisi yang bertentangan dengan nilai kemanusiaan dipertahankan guna menangkal pengaruh negatif dari masyarakat modern yang dipandang dekaden, tidak bermoral, dan fungsional tanpa jiwa.

\section{PENUTUP}

Pandangan mengenai martabat manusia sudah dikenal pada masa Yunani kuno. Konsep ini terus berkembang dan tetap memiliki aktualitas hingga dewasa ini. Pada Abad Pertengahan martabat manusia berkembang dalam dialog dengan pandangan teologi Kristiani terutama

14. Bdk. Gerhard Schweppenhäuser, Grundbegriffe der Ethik zur Einführung, S. 155. 
dengan konsep manusia sebagai citra Allah. Ketika pengaruh dominasi Gereja Abad Pertengahan mulai remang-remang, menyingsinglah fajar akal budi dengan Immanuel Kant sebagai salah seorang pemikir terpenting. Kant merumuskan konsep martabat manusia sebagai sebuah istilah rasional-sekular. Dalam kaca mata Kantian martabat manusia merupakan konsep normatif yang melampaui sekat-sekat budaya, agama, ideologi, dan pandangan tentang hidup baik. Karena itu, konsep martabat manusia dapat dijadikan sebagai basis normatif sebuah tatanan hidup bersama yang multikultural.

\section{DAFTAR RUJUKAN}

Burkard, Franz-Peter. "Würde.” In Peter Precht und Franz-Peter Burkard, Hrsg., Metzler Lexikon Philosophie. Stuttgart/Weimer: Verlag J.B. Metzler, 1999, SS. 671-673.

Habermas, Jürgen. Theorie und Praxis: Sozialphilosophische Studien. Frankfurt am Main: Suhrkamp Verlag, 1982. - Zur Verfassung Europas: Ein Essay. Frankfurt am Main: Suhrkamp, 2011.

Hõffe, Ottfried. Medizin ohne Ethik? Frankfurt am Main: Suhrkamp Verlag, 2002.

Kant, Immanuel. Die Metaphysik der Sitten. Zweiter Teil: Metaphysische Anfangsgründe der Tugendlehre (1798). Stuttgart: Philipp Reclam Verlag, 2001.

. Grundlegung zur Metaphysik der Sitten (1785). Alexander Heine, Hrsg. Essen: Phaidon Verlag, 1992.

Paetzold, Heinz. "Der Mensch." In Martens Ekkehard und Herbert Schnädelbach, Hrsg. Philosophie: Ein Grundkurs. Hamburg: Reinbek, 1985, SS. 440-479.

Schopenhauer, Arthur. "Preisschrift über die Grundlage der Moral." In Arthur Schopenhauer, Werke in zehn Bünden. Band 6. Zülrich: Haffmans Verlag AG, 1977, SS. 41-142.

Schweppenhäuser, Gerhard. Grundbegriffe der Ethik zur Einführung. Hamburg: Junius Verlag GmbH, 2003.

Volpi, Franco, Hrsg. Grosses Werklexikon der Philosophie. Band 1: A bis K. Stuttgart: Alfred Krõner Verlag, 2007. 